\title{
Conference Skills in Remote Learning
}

\author{
Eva Čoupková, Daniela Dlabolová
}

\begin{abstract}
Practising conference skills improves students' language competence for their future careers and increases their motivation to study a foreign language. The project of a "mock scientific conference" developed at the Language Centre at the Faculty of Science of Masaryk University can be seen as an instance of project-based learning. In the first section of our paper, we discuss individual tasks and activities designed for the students at a postgraduate level, including practice in delivering expert talks, writing abstracts and bionotes, organizing the event and performing various roles, such as chairing sessions and leading discussions. The second chapter is devoted to the adaptation of the originally in-class course to the remotelearning environment. It outlines the modifications needed for achieving a successful online communication and the cooperation of students and establishing a meaningful social interaction. Suggestions for an efficient use of interactive online tools, applications and platforms are given that can be employed in enhancing the writing and speaking skills of students.
\end{abstract}

Key words: remote learning, conference simulation, project-based learning, interactive tools, student-autonomy

\section{Introduction}

"These are the times that try men's souls," wrote Thomas Paine in December 1776 in his pamphlet The Crisis, referring to the issues of the American Revolution. Now, at the beginning of 2021, the COVID-19 stricken world faces a situation that, again, affects all the strata of our societies, including teachers and students. The evolution of the present crisis has brought about the need to refine our educational activities, tried and tested methodologies, and usual ways of communicating. We strive to adapt to the new environment of online learning.

Conference skills have been for a long time included in the standard language courses for undergraduate (Bachelor) and postgraduate (Master) students at the Faculty of Science of Masaryk University in Brno. Both the teachers and students see conference skills and resulting conference simulations as an integral part of the education of young scientists. The students feel the need to be able to publicly present the results of their academic and research work and participate at scientific conferences successfully. A great proportion of Master students at the Faculty of Science plan to embark on a career if not directly in primary or secondary research, then at least in institutions conducting surveys, providing data analyses, or developing new materials, approaches and solutions to problems affecting regional or national infrastructure, environment and industry. In various stages of their work, they will be expected to attend or even organize conferences or professional meetings of various kinds and present, discuss, defend or challenge the papers or proposals of themselves or their colleagues. We as language teach- 
ers believe that effective learning should be based on authentic situations that expand the students' dispositions to spontaneous behaviour and creative thinking. Therefore, the methodology of conference simulations strives to build on life-like situations and equip the students with the strategies they will find useful in their future careers.

In the first section of our paper, we discuss conference simulations as an instance of project-based learning (PBL), which means working for a longer period of time on finding a solution to a given (real) problem or becoming prepared to perform an action aimed at fulfilling some (real) task (Parker et al., 2013). The specific stages and tasks are outlined that were integrated into the project and discussed in an earlier article (Dlabolová et al., 2020). All the activities are tailored to the needs of all disciplines taught at our faculty, i.e. physics, mathematics, chemistry, life sciences, geology, and geography. The project was designed mainly for inclass instruction but includes both face-to face and online activities, which proved very convenient during the transformation to its remote format. Therefore, in the second part, we show how we adapted the activities and tasks to the online environments, which platforms and tools were used and found useful, and which benefits and drawbacks we encountered in the course of the development of the online format of the project.

\section{In-class procedure with some online interactive tools}

We have planned conference simulations as a whole-term project. At the beginning of the term, students brainstorm what conference skills comprise. Most of them immediately suggest a paper or poster presentation as an obvious example. However, there are many more tasks to arrange or roles to adopt, not only from the perspective of a paper presenter, but also related to the event organization. During the early discussions about the project, students find out that there are pre-, during and post- arrangements to be made, depending on whether a person is a conference attendee or a conference organizer, or assumes both of these roles. Collectively, they compile role tables that include all the possible tasks. This can be organized as an in-class activity or (and) assigned as homework, so that the students may be engaged in continuous synchronous and asynchronous communication, which supports their collaboration. A useful platform for sharing ideas related to conference organization is, for example, a google.docs table, which is easy to work with for all the students and the teacher.

All the students in the group are expected to act as both conference attendees and organizers. Therefore, the first stages of the project work are devoted to the preparation of paper presentations. We discuss the usual features of an academic presentation, such as relevant content, structure, body language, design of visuals, establishing the contact with the audience, handling questions and reactions to 
them. The most challenging problem for the students is how to prepare a subjectspecific talk that contains expert knowledge but, at the same time, is understandable and rewarding for other students. Quite often our students decide to present the topic of their research project or Bachelor's or Master's theses, which is highly advisable, because then they present their own work or that of their research team, which makes their talk original and authentic. On the other hand, that poses many problems, as they tend to go into much detail and use specialized terminology and concepts which other students might find difficult to understand. This well-illustrates the relevance of audience awareness as an important skill that successful presenters should possess.

When the students try to think about suitable topics and logical structure of their presentations, they also compile abstracts of papers and bionotes. We use authentic sample abstracts and bionotes from real scientific conferences and analyse their content, form and language, in order to motivate the students and provide useful scaffolding models. Students write the first draft of their abstracts and bionotes and upload them into the so called "Homework Vault", which is a very useful application of our Information System. The great advantage of using the university Information System is the fact that the students are already familiar with the opportunities it offers from their previous studies and possess a working knowledge of tools incorporated in it. "Homework Vault" enables students to open the files of their fellow students and make suggestions for improvements; therefore, all the students can see comments and amendments made by all their peers in the group and learn from them. Then, the students prepare the final drafts of their abstracts and bionotes, which are, again, double peer-reviewed and uploaded into a shared online document, such as google.docs. It is a useful platform for the conference organizers using which they may easily collect all the abstract and bionotes needed for the conference programme.

This is closely related to conference organization. It starts with the creation of a call for papers, which is a team and largely autonomous work without much teacher intervention. Again, to make it as authentic as possible, students search the Internet for examples from calls for papers (i.e. Calls for Abstracts, Calls for Proposals...) from areas related to their specializations to see which items are included in these documents. They discuss their content, such as the name of the event, date and venue, objectives, deadlines, or procedure of submitting abstracts and bionotes. The actual call for papers compilation is carried out using an online document, which all the students can access and edit. Students like this activity, especially the creativity involved in thinking about an attractive conference name, sometimes also in defining its objectives. As soon as this team-work is finished, a distribution of roles related to conference organization starts. 
The number of students in our groups varies but it is usually about ten. We appoint one or two volunteers who prepare a conference programme and compile a book of abstracts, which we normally do not print, but produce as online material or a content of a conference website. The students acting as speakers are selected, who give opening and closing speeches, and also session chairs; they introduce speakers and organize discussions after individual presentations. Formal opening and closing speeches and chairing should be prepared and rehearsed by all the students in the group. We remind our students of the fact that welcoming the audience is by its nature a fairly formal speech event. Nonetheless, there are levels of formality to be considered. Chairs of small-scale events will tend to use less formal language than they might at larger events. Students practise this by preparing welcoming and closing speeches for several distinct occasions, such as:

- A workshop session in which they know most of the twenty participants.

- A formal plenary session with an audience of one hundred academics.

- A professional interest meeting at their home university; the audience is made up of fellow students or colleagues.

- An international conference with participants from all over the world.

Students acting as session chairs try to choose the most effective ways to introduce speakers to the audience. They first search for and compare video examples from real conferences. Then they decide which parts should be included in these introductions and which language structures are appropriate. Finally, they read the bionotes of their fellow presenters and try to introduce them, both formally and informally.

This practice makes the students aware of the context dependence of language, thus improving their communicative competence. The science students usually possess superb analytical skills that they have gained through the rigorous study of their disciplines; therefore, it is not difficult for them to recognize and differentiate between formal and informal structures. On the other hand, they sometimes do not quite understand that language is primarily a social phenomenon that does not function in isolation but is heavily dependent on the surrounding context. Bell argues that no language "occurs isolated from its users and their purposes, the temporal and spatial setting, and conventions of social communities" (2014, p.131). Each language user should be able to adapt their speech or writing to a specific situation and understand that a linguistic material that is appropriate in one situation would not function well in a different context. Therefore, our methodology concentrates on providing that experience by showing how to modify language to make it suitable for the given occasion.

Section chairs are expected not only to introduce speakers with their presentations and be responsible for the time management during the talks, but also invite 
the audience to ask questions and lead the discussion. We remind the students of the social and psychological relevance of their role. By a sensitive and tactful introduction of the presenters, they may not only inform the audience, but also help the speakers to overcome their stage fright. After the presentation, they are supposed to acknowledge and thank the speakers by saying something positive about their paper and initiate a successful discussion by providing the audience members with needed encouragement and a good example.

Apart from this "serious" work, we involve a more relaxed activity - informal interaction during a conference break. Students practice small talk suitable for this occasion, which they enjoy, as it makes them aware of different situations they encounter during one social event. This is also a good opportunity for some students to show their skills outside the academic field, because they collectively prepare refreshments, sometimes even home-made.

\section{Adaptation to the remote-learning environment}

The standard realization of the Conference Skills project takes place in the classroom with students being physically present and collaborating with each other face to face. When the educational activities suddenly happened to be limited by anti-pandemic measures, we transferred the project to the online environment. The change was not very complicated as many of the components had had the format of blended learning which combined face to face classroom interaction with computer-based activities. We decided to conduct the online meetings via the Microsoft Teams application which is the official university platform with established student access. Thus, the needs of student-users had already been catered for. For the teachers, it was essential to get acquainted with the offered functions and settings and select the practical ones so that the tool was easy to use. Similar to other educators, we set up individual teams for different study groups, added channels for communication within each team and planned regular meetings. Later the new feature of break-out rooms was provided, which enabled us to support the collaborative character more effectively when we had students working synchronously in small groups or pairs.

The use of technology for the meetings of teachers and students might feel discouraging but since the teacher role is changing, this experience has somewhat accelerated the shift to a partner-like relationship when students sometimes suggest how to deal with technical difficulties. It is the teacher who needs to act as a mediator of advanced academic skills in a flexible way without having ready solutions to potential challenges. The teacher designs the project structure, sets the goals and creates conditions for working within the given framework. During the online meetings, the teacher directs students towards the use of authentic models or examples to provide scaffolding for progress in new areas of academic language. 
In the collaborative nature of learning, students are able to experience success and recognition if they take active part in the process. The positive motivation and degree of autonomy in making decisions, especially concerning the content which fills the given structure, put the learners in the role of active progress constructors.

What we find specific when starting an online collaborative project is paying sufficient attention to the social factors. Not all participants know the other people in the team and communicate in a spontaneous manner. Some prefer not to speak much; undoubtedly, the way of joining the seminars via electronic devices limits the possibilities for social conversation and establishing friendly relationships. On the other hand, others seem at ease, free from the stress of speaking in front of the full classroom when all students are physically present. The physical distance in general does mean an obstacle, often fostered by the possibility to stay off the camera. In such situations, the team members may feel anonymous and the lack of shared background brought about by traditional course attendance makes it harder to create a positive atmosphere for collaboration. To overcome the barrier, we think it is essential for the team members to switch on their webcams. Some are not used to it because it is not common in other courses, particularly during lectures when they are not required to interact with each other. For these reasons, we decided to set the use of the webcam as our course requirement. Then we employ different ice-breakers and student activating methods to make sure that the participants are comfortable. For example, it is welcome to let the teammates step into one's privacy when the webcam zooms part of rooms in the homes. Thus, we are able to see for example sports cups, medals, posters, collections of artefacts or exotic plants which demonstrate the achievements and interests of their owners. By doing some micro-activities in the initial phases of our meetings we try to compensate for the lack of common classroom interaction and establish the feelings of safety and trust. The micro-tasks sometimes involve physical movement as well, such as voting with hands instead of clicking or a game which includes showing objects or cards on the screens.

Lonka and Ketonen claim that "meaningful learning aiming at conceptual change and understanding is most likely to develop in meaningful social interaction." (2012, p. 66). Similarly, we argue that the motivating social environment in the online team prepares conditions for the transformation of separated learners with specific skills and knowledge into teammates willing to contribute their erudition to achieving a collaborative outcome. Only after evoking a positive atmosphere can the learners be pushed slightly out of their comfort zones into creating new language constructs and playing new roles required by the mock conference project, the roles of conference organizers, conference speakers, authors of specific texts and presentations and mediators of the flow of knowledge. These new outputs constitute a substantial amount of original content made independently by our 
learners. As such, it is worth displaying and sharing both the components and the integrating idea on an online platform.

In the recent run of the project we used Google Sites application for creating a website of a mock conference. It provided the information about the event in a well-organized form so that anyone could read it and find details similar to those of a real scientific conference. The teacher created the site and prepared the structure with several sub-pages. Each team had a different website because they had different focus and themes. After getting the editing rights, the students started to fill the individual parts with their content. The main page displayed the conference title and the call for papers as an invitation to the event. The other sub-pages showed the conference programme with the allocated times, the final versions of the presentation abstracts and bionotes of the speakers. This simple website represented the progress of the study group similarly to a portfolio, showing the extent of acquired skills of writing texts in new academic genres. Moreover, it was the product of the organization of an event which simulates a real-world situation related to the students' careers. The careful elaboration and comprehensibility of the final form make this product ready for efficient sharing in the academic community.

Various interactive tools can be employed to refine the quality of the outcomes before their publication on Google Sites. Two examples of simple and effective means are the online forum and the Mentimeter application. Via a forum we are able to organize the participants' ideas and the reactions to these ideas. This is helpful when students choose a topic for their conference presentation. As mentioned above, frequently it is difficult for the speakers to provide a comprehensible description of one's scientific topic. To reconcile the different expectations of the presenters and their audience, students are asked first to post a few sentences about their topic on the forum. They should express briefly but precisely what they would like to cover in their conference speech. Next, they react to the posts of several other teammates. Due to the written form, these ideas get carefully formulated and communicated with some degree of clarity. The readers' reaction to unfamiliar topics reveal if the descriptions are understood well and may motivate the authors to adopt a different approach or modify their language. Scientific concepts are more comprehensible when mediated by means of appropriate rhetorical functions, such as cause and effect or sequencing. Useful tools for learning the functions are the publicly available websites about writing skills in higher education, for example UEfAP - Rhetorical Functions in Academic Writing under the link http://www.uefap.com/writing/function/function.htm. Minor language modifications might appear in the form a synonym, simile, or even a metaphor. If appropriate, it can be said that, for instance, "meander" is a "bend" or "enzymes" are "workhorses of life." 
Another important feedback opportunity is during the design of graphs, pictures or diagrams for the conference presentation. These visuals need detailed elaboration due to the demands for the instant conveying of complex information. In an online presentation, it is harder to understand quickly the main points and good visuals are key to success. Therefore, during the preparation, students consider different types of visuals and purposes for which they are suitable. As an exercise, they try to express a message of a given text by means of an appropriate diagram, such as a pie chart, a fishbone scheme or a tree diagram, etc. An interactive tool for providing peer-feedback is available on www.mentimeter.com. This application offers a range of formats for real-time interaction. We used a scales slide which enables expressing opinions on several criteria within a numerical scale from the worst to the best value. The criteria can be formulated as statements, for example "The type of visual representation is accurate," or "It is easy to see the main point," etc. The participants then click on a value for each statement and the average score is displayed on a picture showing a bar for each statement. This tool helps to provide immediate feedback for the authors who can adapt the content of their presentations and thus enhance the comprehensibility.

The participation in an online mock conference is a significant opportunity to develop one's knowledge and skills. It helps to build and reinforce one's confidence in remote communication and to understand practical steps for organizing an event. Learners get acquainted with the complexity of the life-like undertaking and the strategies for dealing with multiple demands of the stakeholders. They are guided through the process of breaking the project into smaller parts, structuring the steps and observing strict time-management. They see the importance of empathy in communication and the effects of targeted feedback. In accordance with other educators, we believe that "it is important to design ways of teaching and learning that promote engagement and active learning." (Lonka \& Ketonen, 2012, p. 64). By its character, the Conference Skills project creates the conditions for active and autonomous engagement when students have both the control and responsibility in the process of learning in their team.

\section{Conclusion}

The paper discussed one example of implementation of the methodology of project-based learning in the form of conference skills practice tasks designed for the postgraduate students of Science. The aim of the project was to provide our students with useful strategies and knowledge they could employ in their future careers and solving real-life situations. Originally designed mainly as a face-to face classroom project with a sequence of logically connected tasks requiring active student involvement in planning and realization of all its individual stages, it was later, in order to comply with the anti-epidemic measures, adapted to the online format. That required employing online tools and platforms enabling remote 
communication and using them in ways that fostered student-collaboration and effective and rewarding social interaction.

We believe that this methodology may provide useful inspiration to other educators striving to develop both in-class and online courses incorporating spontaneous and authentic learning environment.

\section{References}

BELl, A. (2014). The Guidebook to Sociolinguistics. John Wiley \& Sons.

Dlabolová, D., Suchomelová-PoŁomska, A., Čoupková, E. (2020). Conference Skills in Practice. Porta Lingua 2020, SZOKOE, 311-320. DOI: https://doi.org/10.48040/PL.2020.25

LonkA, K., Ketonen, E. (2012). How to make a lecture course an engaging learning experience? Studies for the Learning Society 2(2-3), 63-74. DOI: 10.2478/v10240-012-0006-1

Paine, T. (1776). The Crisis. Independence Hall Association. (1995, July 4). https://www.ushistory.org/ Paine/crisis/c-01.htm

Parker, W. C., Lo, J., Valencia, S. W., Nguyen, D., Abbott, R. D., Nolen, S. B., Bransford, J. D., And Vye, N. J. (2013). Beyond breadth-speed-test: Toward deeper knowing and engagement in an advanced placement course. American Educational Research Journal, 50(6), 1424-1459.

\section{Authors}

Mgr. Eva Čoupková, Ph.D., e-mail: coupkova@sci.muni.cz, Masaryk University Language Centre Author is an assistant professor at the Language Centre of Masaryk University in Brno. She teaches Academic English and English for Specific Purposes for Mathematics and Physics students at the Faculty of Science of that university. Her field of interest is Gothic Literature and English Romanticism of the late eighteenth and early nineteenth century. She obtained her PhD in 2003 from Palacký University in Olomouc for her dissertation on Gothic Novel and Drama as two related genres of English literature.

In the area of English for Specific Purposes methodology her research is devoted to the innovative approaches employed in collaborative learning and the development of authentic tasks and projects for Science students building on the methodology of project-based learning.

Mgr. Daniela Dlabolová, e-mail: dlabolova@sci.muni.cz, Masaryk University Language Centre Author is a lecturer at the Language Centre of Masaryk University in Brno. She studied English Language and Literature at the Faculty of Arts of the same institution. Her academic interests were related to the study of nonconformist approaches in the development of the novel as a new genre in English literature. At present she teaches Academic English and English for Specific Purposes to the students of Natural Sciences, namely Chemistry and Geography. She is interested in innovative methodology and the process of course design. She has recently been involved in collaborative and project-based learning with the aim to support student autonomy, creativity, and sense of competence in dealing with complex tasks. 